\title{
Effectiveness and Durability of the Rice Pi-ta Gene in Yunnan Province of China
}

\author{
Jinbin Li, Lin Lu, Yulin Jia, and Chengyun Li
}

First author: Agricultural Environment and Resources Research Institute, and second author: Flower Research Institute, Yunnan Academy of Agricultural Sciences, Kunming, Yunnan Province 650205, China; third author: U.S. Department of Agriculture-Agricultural Research Service, Dale Bumpers National Rice Research Center, Stuttgart, AR; and fourth author: The Ministry of Education Key Laboratory for Agricultural Biodiversity and Pest Management, Yunnan Agricultural University, Kunming, Yunnan Province 650201, China. Accepted for publication 9 January 2014.

\begin{abstract}
Li, J., Lu, L., Jia, Y., and Li, C. 2014. Effectiveness and durability of the rice Pi-ta gene in Yunnan Province of China. Phytopathology 104:762-768.

Rice blast is one of the most damaging diseases of rice worldwide. In the present study, we analyzed DNA sequence variation of avirulence $(A V R)$ genes of AVR-Pital in field isolates of Magnaporthe oryzae in order to understand the effectiveness of the resistance gene Pi-ta in China. Genomic DNA of 366 isolates of M. oryzae collected from Yunnan province of China were used for polymerase chain reaction (PCR) amplification to examine the existence of AVR-Pital using gene-specific PCR markers. Results of PCR products revealed that 218 isolates of M. oryzae carry AVR-Pital. Among of them, 62.5, 56.3, 58.5, 46.7, 72.4, and $57.4 \%$ of $M$. oryzae carry AVR-Pital from northeastern, southeast,
\end{abstract}

ABSTRACT

Rice blast, caused by the filamentous ascomycetous fungus (Magnaporthe oryzae), is one of the most damaging diseases of rice worldwide. Practically, blast disease is managed by the use of resistant cultivars carrying both major and minor resistance $(R)$ genes and application of fungicides integrated with cultural practices. Among them, use of resistant cultivars is the most economical and environmentally benign method of reducing crop loss due to blast.

Major $R$-gene-mediated resistance is effective in recognizing the strains of $M$. oryzae that contain the corresponding avirulence $(A V R)$ gene. Thus far, nine $A V R$ genes in $M$. oryzae have been cloned: AVR-Pita (22), AVR-Pizt (20), AVR1-CO39 (6), ACE1 (8), AVR-Pia (32), AVR-Pii (32), AVR-Pik/km/kp (32), PWLl (15), and PWL2 (28).

The effectiveness and durability of major $R$-gene-mediated resistance is determined by structural and functional integrity of $A V R$ genes. The AVR-Pita gene of M. oryzae determines the efficacy for Pi-ta. AVR-Pita encodes a predicted metalloprotease with 223 amino acids (22). AVR-Pital, renamed from AVR-Pita, is a member of the AVR-Pita alleles in isolates of $M$. oryzae (16). The variants of $A V R$-Pital, including point mutations, insertions, and deletions, were found in the field isolates from the United States, China, Colombia, India, Egypt, and the Philippines (5). Specific alterations of the active site from glutamic acid to aspartic acid (E177D) and substitutions of methionine to tryptophan (M178W) in the putative protease motif of strain 4360-R-62 resulting in the loss of avirulence were observed (12).

Corresponding authors: C. Li; E-mail address: li.chengyun@gmail.com Y. Jia; E-mail address: Yulin.Jia@ ars.usda.gov

http://dx.doi.org/10.1094/PHYTO-11-13-0302-R

(C) 2014 The American Phytopathological Society western, northwest, southwestern, and central Yunnan province, respectively. The detection rate of AVR-Pital was, in order: southwestern > northeastern $>$ western $>$ central $>$ southeastern $>$ northwestern Yunnan province. Moreover, in total, 18 AVR-Pital haplotypes encoding 13 novel AVR-Pital variants were identified among 60 isolates. Most DNA sequence variation was found to occur in the exon region, resulting in amino acid substitution. Six virulent haplotypes of AVR-Pital to Pita were identified among 60 field isolates. The AVR-Pital has evolved to virulence from avirulent origins via base substitution. These findings demonstrate that AVR-Pital is under positive selection and mutations of $A V R$-Pital are responsible for defeating race-specific resistance in nature.

Additional keyword: effector.

$P i$-ta has been effective in preventing blast disease in the United States since its release in 1990 (21). In China, the Pi-ta gene was found in 71 leading cultivars or hybrid rice parents in most rice-producing provinces (31) and in 72 landraces from Yunnan province $(19,31)$. A single amino acid in the leucine-rich repeat (LRR) domain in one resistant $P i$-ta haplotype is essential for AVR-Pita recognition (12,17). In contrast, 38 AVR-Pital haplotypes encoding 27 AVR-Pital variants were identified among 151 avirulent isolates collected worldwide. Most DNA sequence variations were found to occur in the exon region resulting in amino acid substitutions, suggesting that $A V R$-Pital is under positive selection and mutations of AVR-Pital are responsible for defeating race-specific resistance in nature (5). Thus far, the documented AVR-Pital mutations in field isolates of M. oryzae from the United States also included the Pot3 transposon insertion (33); whereas, in field isolates from Japan, deletion of functional copies and base substitutions were observed (30). The AVR-Pita allele was detected in fields isolates collected from Jilin province of China by AVR-Pita-specific markers. In total, 89 AVR-Pita alleles of 103 isolates have been amplified; however, structural and functional relations of the variants have not been analyzed (27).

The objective of the present study was to analyze DNA sequence variation of AVR-Pital in field isolates of M. oryzae in order to understand the effectiveness and durability of Pi-ta in Yunnan province of China.

\section{MATERIALS AND METHODS}

Rice cultivars, fungal isolates, culture, and pathogenicity assays. The Pi-ta-containing rice monogenic line IRBLta-K1 and the susceptible backcrossing parent Lijiangxintuanheigu (LTH without $P i$-ta) were used for pathogenicity assays. In total, 
366 isolates were collected, single-spore purified, and examined. All isolates were stored at $-20^{\circ} \mathrm{C}$ on filter paper and grown at room temperature under blue and white fluorescent lighting on petri dishes containing oatmeal agar for spore production. Disease reactions were determined using a modified standard pathogenicity assay, as previously described by Jia et al. (13). Specifically, rice seedlings at the three- to four-leaf stage were placed in a plastic bag and spray inoculated with a spore suspension at 1 to $5 \times 10^{5} \mathrm{spores} / \mathrm{ml}$. After inoculation, the plastic bags were sealed, to maintain high humidity, for $24 \mathrm{~h}$ before removing the plants from bags. Subsequently, plants were maintained in a greenhouse for an additional 6 days to allow the development of clear disease symptoms. The disease reactions were rated based on visual number and amount of lesions at the second youngest leaf using disease scale where 0 to $2=$ resistant and 3 to $5=$ susceptible.

DNA preparation, polymerase chain reaction amplification, and DNA sequencing. Fungal isolates were grown in complete liquid media at $25^{\circ} \mathrm{C}$ for 6 to 8 days to produce mycelium under dark conditions. DNA was then isolated from mycelia using the cetyltrimethylammonium bromide method (29). Primers YL169 (5'-CGACCCGTTTCCGCC-3') and YL149 (5'-TGACCGCG ATTCCCTCCATT- $3^{\prime}$ ) were used to amplify the AVR-Pital allele and for sequencing using methods described by Dai et al. (5). Specifically, polymerase chain reaction (PCR) was performed using 2x Taq PCR MasterMix (Tiangen Biotech Co. Ltd., Beijing). Each PCR consisted of the following components: $25 \mu \mathrm{l}$ of Taq PCR Master Mix (containing $25 \mathrm{U}$ of Taq DNA polymerase, 10x Tiangen PCR buffer, $15 \mathrm{mM} \mathrm{MgCl}_{2}$, and $200 \mu \mathrm{M}$ each dNTP), $1 \mu \mathrm{l}$ of each $10 \mu \mathrm{M}$ primer, $2 \mu \mathrm{l}$ of fungal genomic DNA, and $21 \mu \mathrm{l}$ of distilled water (provided by Tiangen Kit). Reactions were performed in a Bio-Rad Thermal Cycler (C1000; Bio-Rad Laboratories, Life Science Research, Hercules, CA) with the following PCR program: 1 cycle at $95^{\circ} \mathrm{C}$ for 3 min for initial denaturation; followed by 29 cycles at $95^{\circ} \mathrm{C}$ for $30 \mathrm{~s}, 60^{\circ} \mathrm{C}$ for $30 \mathrm{~s}$, and $72^{\circ} \mathrm{C}$ for $30 \mathrm{~s}$; and a final extension of $72^{\circ} \mathrm{C}$ for $7 \mathrm{~min}$. All PCRs were repeated three times ( $20 \mu \mathrm{l}$ for detection, $50 \mu \mathrm{l}$ for sequencing). The size of the amplified fragment was estimated by DL2000 DNA Ladder (Tiangen Biotech Co. Ltd.). PCR products were sequenced using the same primers as previously mentioned above for PCR amplification. DNA was sequenced by Shanghai Life Technologies Biotechnology Co., Ltd. (Shanghai, China). Each isolate was sequenced three times.

Data analysis. DNA sequences of AVR-Pital were assembled by Vector NTI software Suite V.10 (Invitrogen, Carlsbad, CA) and aligned using DNASTAR V7.10 software (http://www. dnastar.com/). The number of DNA haplotypes, polymorphic sites $(\pi)$, and the sliding window were calculated using DnaSP v5.10.01 software (25). Haplotype network analysis was performed using TCS1.21 (http://darwin.uvigo.es/) (3). Diversity index was calculated as the frequency of haplotypes or protein types in the rice blast fungus population following Fontaine's method (7): diversity index $=\left(1-\sum_{i=1}^{n} p_{i}{ }^{2}\right)$ (where $p_{i}$ is the frequency of the haplotype $i$ in a population).

\section{RESULTS}

Effectiveness of the Pi-ta gene. Based on disease reactions, 239 of the 366 isolates tested were avirulent to the Pi-ta-containing rice monogenic line IRBLta-K1, while the remaining 127 isolates were virulent (Table 1). Of 366 isolates, 218 AVR-Pital alleles were amplified by AVR-Pital-specific primers (YL149/ YL169) (Table 1); the average percentage of AVR-Pital was $59.6 \%$. The highest percentage of AVR-Pital was $72.4 \%$ in the $M$. oryzae population collected from southwestern Yunnan whereas the lowest was $46.7 \%$ from northwestern Yunnan (Table 1). The percentages of AVR-Pital were 56.3, 57.4, 58.5, and $62.5 \%$ in southeastern, central, western, and northeastern Yunnan province, respectively. These findings suggest that $P i$-ta is still useful to most rice production areas in Yunnan province.

Haplotype diversity of $\boldsymbol{A V R}$-Pital of $\boldsymbol{M}$. oryzae. In total, 18 $A V R$-Pital haplotypes, including the original AVR-Pital, were identified based on the DNA sequence assemblies of 60 isolates (Table 2). Nine haplotypes were detected in $25 \mathrm{M}$. oryzae from western Yunnan. Six, five, three, three, and two haplotypes were detected in $14,7,8,4$, and $2 M$. oryzae from northeastern, southeastern, central, northwestern, and southwestern Yunnan, respectively (Table 3). Similarly, the diversity index was $0.78,0.77$, $0.76,0.63,0.50$, and 0.41 for southeastern, western, northeastern, northwestern, southwestern, and central Yunnan, respectively (Table 3). In summary, the diversity index of AVR-Pital was ordered in Yunnan province as southeastern $>$ western $>$ northeastern $>$ northwestern $>$ southwestern $>$ central.

AVR-Pital is known to have three introns and four exons in the open reading frame (ORF) (22). High nucleotide variation in the exons of AVR-Pital was observed (Fig. 1), and a haplotype network based on sequence variation was developed (Fig. 2). Four major evolutionary clusters (Fig. 2A to D) of AVR-Pital were observed among 60 field isolates. The isolates of cluster $\mathrm{C}$ and other less frequent haplotypes of AVR-Pital were avirulent to IRBLta-K1 (with Pi-ta) (Fig. 2; Table 4). The isolates in H11, $\mathrm{H} 15$, and $\mathrm{H} 16$ of cluster $\mathrm{A} ; \mathrm{H} 17$ of $\mathrm{B}$; and $\mathrm{H} 3$ of D were virulent to rice cultivars with $\mathrm{Pi}$-ta (Fig. 2; Table 4). These findings suggest that the A, B, and D clusters of AVR-Pital were evolved to virulence from avirulent origins via nucleotide substitution, resulting in avoiding recognition of $\mathrm{Pi}$-ta in nature. The virulent isolates of H11 and H16 were identified in southeastern, H15 in western, and H17 in northeastern and central Yunnan, China, suggesting that the virulent evolution of AVR-Pital occurred in most rice-producing regions of Yunnan (Fig. 2; Tables 3 and 4). Among 18 haplotypes identified, 7 haplotypes were identified in multiple isolates whereas 11 haplotypes were identified only in a single isolate (Table 2). The original AVR-Pital allele was found in 10 isolates (Table 2). Alignment of the AVR-Pital DNA sequences from 60 isolates revealed that there were 22 polymorphic sites (excluding gaps), with 19 being in the exon region and 3 in the intron region. Of the 19 sites in the exon region, 17 resulted in amino acid substitutions (Table 4), indicating that most of the variation in the exon region resulted in alteration of the amino

TABLE 1. Distribution of avirulence (AVR)-Pital genes and AVR isolates of Magnaporthe oryzae collected from Yunnan, China to IRBLta-K1

\begin{tabular}{|c|c|c|c|c|c|}
\hline \multirow[b]{2}{*}{ Locations } & \multirow[b]{2}{*}{ Number of isolates } & \multicolumn{2}{|l|}{ PCR detection $^{a}$} & \multicolumn{2}{|c|}{ Pathogenicity assayb } \\
\hline & & Number of isolates with AVR-Pital & Frequency $(\%)$ & Number of AVR isolates & Frequency $(\%)$ \\
\hline Northeastern & 72 & 45 & 62.5 & 58 & 80.6 \\
\hline Southeast & 32 & 18 & 56.3 & 9 & 28.1 \\
\hline Western & 164 & 96 & 58.5 & 110 & 67.1 \\
\hline Northwest & 15 & 7 & 46.7 & 11 & 73.3 \\
\hline Southwestern & 29 & 21 & 72.4 & 18 & 62.1 \\
\hline Central & 54 & 31 & 57.4 & 33 & 61.1 \\
\hline Total & 366 & 218 & 59.6 & 239 & 65.3 \\
\hline
\end{tabular}

a $\mathrm{PCR}=$ polymerase chain reaction.

b Indicates pathogenicity assay on monogenic line IRBLta-K1 (containing Pita). 
acids in the protein. Moreover, the AVR-Pital sequences among the 60 isolates were predicted to produce 14 functional proteins (Table 4). Among these 14 proteins, amino acid variations were predicted to occur at 17 positions, including an insertion/deletion. All variations occurred throughout the protein, including position 173 of the putative protease motif (Table 4). The protease motif in the 14 putative proteins was identical except for the 173rd amino acid, V173I, in the metalloprotease motif (22). Amino acid variations at D55N were found in six isolates, five of which were virulent on monogenic line IRBLta-K1 (with $P i-t a$ ) (Table 4), suggesting that amino acid 55D is critical for avirulent function of AVR-Pita.

The AVR-Pital gene was not amplified from 61 of 127 virulent isolates and 87 of 239 avirulent isolates (Table 5). Nearly half of virulent isolates were amplified with AVR-Pital, suggesting that there are additional factors that are critical for avirulence. Similarly, AVR-Pital was not amplified from $36.4 \%$ avirulent isolates, suggesting that AVR-Pital primers may be not specific for these isolates or $R$ genes for these isolates are $P i$ - $t a$ independent. There are 152 avirulent isolates on IRBLta-K1 with $P i$-ta containing $A V R$-Pital and 61 virulent isolates without AVR-Pital. There are $58.2 \%$ of isolates that belong to both reaction types, which is consistent with the gene-to-gene theory (Table 5). In contrast, 87 avirulent isolates on IRBLta-K1 (Pi-ta) without AVR-Pital, 66 virulent isolates containing AVR-Pital, and $41.8 \%$ of isolates belonging to both reaction types, which is inconsistent with the gene-to-gene theory (Table 5). There were 29.2 to $66.7 \%$ of isolates from the six rice-producing regions of Yunnan, which

TABLE 2. Haplotypes of AVR-Pital in rice blast fungus of Yunnan, China

Variant locus ${ }^{\mathrm{c}}$

\begin{tabular}{|c|c|c|c|c|c|c|c|c|c|c|c|c|c|c|c|c|c|c|c|c|c|c|c|c|c|c|c|}
\hline Haplotype & $N^{\mathrm{a}}$ & $\%^{\mathrm{b}}$ & $17-18$ & 18 & 63 & 163 & $234-235$ & $249-250$ & 260 & 276 & 298 & 300 & 316 & 319 & 365 & 456 & 460 & 517 & 559 & 573 & 716 & 724 & 758 & 759 & 778 & 827 & 874 \\
\hline AF207841 & $\ldots$ & $\ldots$ & $\ldots$ & A & $\mathrm{C}$ & $\mathrm{G}$ & - & - & $\mathrm{T}$ & $\mathrm{T}$ & A & $\mathrm{G}$ & G & $\mathrm{T}$ & $\mathrm{G}$ & $\mathrm{G}$ & $\mathrm{G}$ & $\mathrm{C}$ & G & $\mathrm{G}$ & A & $\mathrm{G}$ & $\mathrm{T}$ & $\mathrm{T}$ & $\mathrm{G}$ & A & $\mathrm{T}$ \\
\hline EF616489 & $\ldots$ & $\ldots$ & GTT & $\cdot$ & $\cdot$ & $\cdot$ & - & - & $\mathrm{C}$ & . & G & . & A & . & $\mathrm{T}$ & . & A & . & . & A & . & . & A & - & A & . & . \\
\hline H01 & 10 & 16.7 & $\ldots$ & $\cdot$ & $\cdot$ & . & - & - & . & . & . & . & $\cdot$ & · & · & . & . & . & . & . & . & · & . & . & $\cdot$ & . & . \\
\hline H02 & 1 & 1.7 & $\ldots$ & $\cdot$ & A & . & - & - & . & . & . & . & . & . & . & . & . & . & . & . & . & . & . & . & . & . & . \\
\hline H03 & 1 & 1.7 & $\ldots$ & $\cdot$ & $\cdot$ & A & - & - & . & . & . & . & . & . & . & . & . & . & . & . & . & . & . & . & . & . & . \\
\hline H04 & 1 & 1.7 & $\ldots$ & G & $\cdot$ & . & - & - & . & . & . & . & . & . & . & . & . & . & . & $\cdot$ & $\cdot$ & . & . & . & . & . & $\cdot$ \\
\hline H05 & 11 & 18.3 & GTT & $\cdot$ & $\cdot$ & . & - & - & . & . & . & . & $\cdot$ & $\cdot$ & . & . & . & . & . & . & $\mathrm{T}$ & $\mathrm{C}$ & . & $\cdot$ & . & . & A \\
\hline H06 & 1 & 1.7 & GTT & $\cdot$ & $\cdot$ & . & - & - & . & . & . & . & A & $\mathrm{C}$ & . & . & . & $\mathrm{G}$ & $\mathrm{T}$ & . & $\cdot$ & $\cdot$ & . & . & . & . & $\cdot$ \\
\hline H07 & 1 & 1.7 & GTT & $\cdot$ & $\cdot$ & . & - & - & . & G & . & . & . & . & . & . & . & . & . & . & $\mathrm{T}$ & $\mathrm{C}$ & $\cdot$ & . & . & . & A \\
\hline H08 & 9 & 15.0 & GTT & $\cdot$ & . & . & - & - & $\mathrm{C}$ & . & G & A & A & . & $\mathrm{T}$ & $\cdot$ & . & . & . & A & G & · & A & - & A & . & $\cdot$ \\
\hline H09 & 3 & 5.0 & GTT & $\cdot$ & . & . & - & - & $\mathrm{C}$ & . & $\mathrm{G}$ & A & A & . & $\mathrm{T}$ & . & A & . & . & A & . & . & A & - & A & . & . \\
\hline H10 & 1 & 1.7 & GTT & $\cdot$ & $\cdot$ & . & - & - & $\mathrm{C}$ & . & G & A & A & . & $\mathrm{T}$ & . & A & . & . & A & G & . & A & - & A & . & . \\
\hline H11 & 2 & 3.3 & GTT & $\cdot$ & . & . & - & - & $\mathrm{C}$ & . & $\mathrm{G}$ & A & A & . & $\mathrm{T}$ & $\mathrm{C}$ & $\cdot$ & . & . & A & $\mathrm{G}$ & . & A & - & A & . & . \\
\hline H12 & 12 & 20.0 & GTT & $\cdot$ & $\cdot$ & . & - & - & $\mathrm{C}$ & . & $\mathrm{G}$ & A & A & . & $\mathrm{T}$ & . & A & . & . & A & $\mathrm{G}$ & . & A & - & A & G & . \\
\hline H13 & 1 & 1.7 & GTT & $\cdot$ & $\cdot$ & . & - & $\mathrm{C}$ & $\mathrm{C}$ & . & $\mathrm{G}$ & A & A & . & $\mathrm{T}$ & . & A & . & . & A & $\mathrm{G}$ & . & A & - & A & . & $\cdot$ \\
\hline H14 & 1 & 1.7 & GTT & $\cdot$ & $\cdot$ & . & A & - & $\mathrm{C}$ & . & G & $\mathrm{A}$ & A & . & $\mathrm{T}$ & . & A & . & . & A & $\mathrm{G}$ & . & A & - & A & . & . \\
\hline H15 & 1 & 1.7 & GTT & $\cdot$ & $\cdot$ & $\mathrm{A}$ & - & - & $\mathrm{C}$ & . & G & A & A & . & $\mathrm{T}$ & . & $\cdot$ & . & . & A & $\mathrm{G}$ & . & A & - & A & . & $\cdot$ \\
\hline H16 & 1 & 1.7 & GTT & $\cdot$ & $\cdot$ & $\mathrm{A}$ & - & - & $\mathrm{C}$ & . & G & A & A & . & $\mathrm{T}$ & $\mathrm{C}$ & . & . & . & A & $\mathrm{G}$ & . & A & - & A & . & . \\
\hline H17 & 2 & 3.3 & GTT & $\cdot$ & $\cdot$ & $\mathrm{A}$ & - & - & $\mathrm{C}$ & . & G & A & A & $\cdot$ & $\mathrm{T}$ & . & A & . & . & A & $\mathrm{G}$ & . & A & - & A & G & . \\
\hline H18 & 1 & 1.7 & GTT & $\cdot$ & $\cdot$ & A & - & - & $\mathrm{C}$ & G & G & A & A & . & $\mathrm{T}$ & . & A & . & . & A & G & . & A & - & A & G & . \\
\hline
\end{tabular}

a Number of isolates.

b Percentage of total.

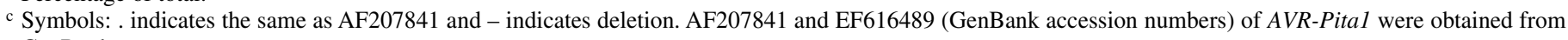
GenBank.

TABLE 3. Distribution of AVR-Pital haplotype in different rice-growing-regions

\begin{tabular}{|c|c|c|c|c|c|c|c|c|}
\hline \multirow[b]{2}{*}{ Haplotype } & \multicolumn{2}{|c|}{ Isolates } & \multicolumn{6}{|c|}{ Regions $^{\mathrm{a}}$} \\
\hline & Number & $\%$ & Northeastern & Central & Southeastern & Western & Northwestern & Southwestern \\
\hline H01 & 10 & 16.7 & $2(14.3)$ & 0 & 0 & $8(32.0)$ & 0 & 0 \\
\hline $\mathrm{H} 02$ & 1 & 1.7 & 0 & 0 & 0 & $1(4.0)$ & 0 & 0 \\
\hline $\mathrm{H} 03$ & 1 & 1.7 & 0 & 0 & 0 & $1(4.0)$ & 0 & 0 \\
\hline $\mathrm{H} 04$ & 1 & 1.7 & $1(7.1)$ & 0 & 0 & 0 & 0 & 0 \\
\hline H05 & 11 & 18.3 & $5(35.7)$ & 0 & $2(28.6)$ & $3(12.0)$ & 0 & $1(50.0)$ \\
\hline H06 & 1 & 1.7 & 0 & 0 & 0 & $1(4.0)$ & 0 & 0 \\
\hline H07 & 1 & 1.7 & 0 & 0 & 0 & $1(4.0)$ & 0 & 0 \\
\hline H08 & 9 & 15.0 & 0 & 0 & 0 & $8(32.0)$ & $1(25.0)$ & 0 \\
\hline H09 & 3 & 5.0 & 0 & 0 & 0 & $1(4.0)$ & $2(50.0)$ & 0 \\
\hline H10 & 1 & 1.7 & 0 & 0 & $1(14.3)$ & 0 & 0 & 0 \\
\hline H11 & 2 & 3.3 & 0 & 0 & $1(14.3)$ & 0 & 0 & $1(50.0)$ \\
\hline H12 & 12 & 20.0 & $4(28.6)$ & $6(75.0)$ & $2(28.6)$ & 0 & 0 & 0 \\
\hline H13 & 1 & 1.7 & 0 & $1(12.5)$ & 0 & 0 & 0 & 0 \\
\hline H14 & 1 & 1.7 & 0 & 0 & 0 & 0 & $1(25.0)$ & 0 \\
\hline H15 & 1 & 1.7 & 0 & 0 & 0 & $1(4.0)$ & 0 & 0 \\
\hline H16 & 1 & 1.7 & 0 & 0 & $1(14.3)$ & 0 & 0 & 0 \\
\hline H17 & 2 & 3.3 & $1(7.1)$ & $1(12.5)$ & 0 & 0 & 0 & 0 \\
\hline H18 & 1 & 1.7 & $1(7.1)$ & 0 & 0 & 0 & 0 & 0 \\
\hline Total & 60 & 100 & 14 & 8 & 7 & 25 & 4 & 2 \\
\hline$N^{\mathrm{b}}$ & $\ldots$ & $\ldots$ & 6 & 3 & 5 & 9 & 3 & 2 \\
\hline $\mathrm{DI}^{\mathrm{c}}$ & $\ldots$ & $\ldots$ & 0.76 & 0.41 & 0.78 & 0.77 & 0.63 & 0.50 \\
\hline
\end{tabular}

a Number and frequency (in parentheses) of isolates of each haplotype.

b Number of haplotypes.

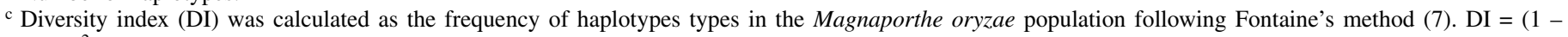
$\sum_{i=1}^{\mathrm{n}} p_{i}{ }^{2}$ ) (where $p_{i}$ is the frequency of the haplotype $i$ in a population). 


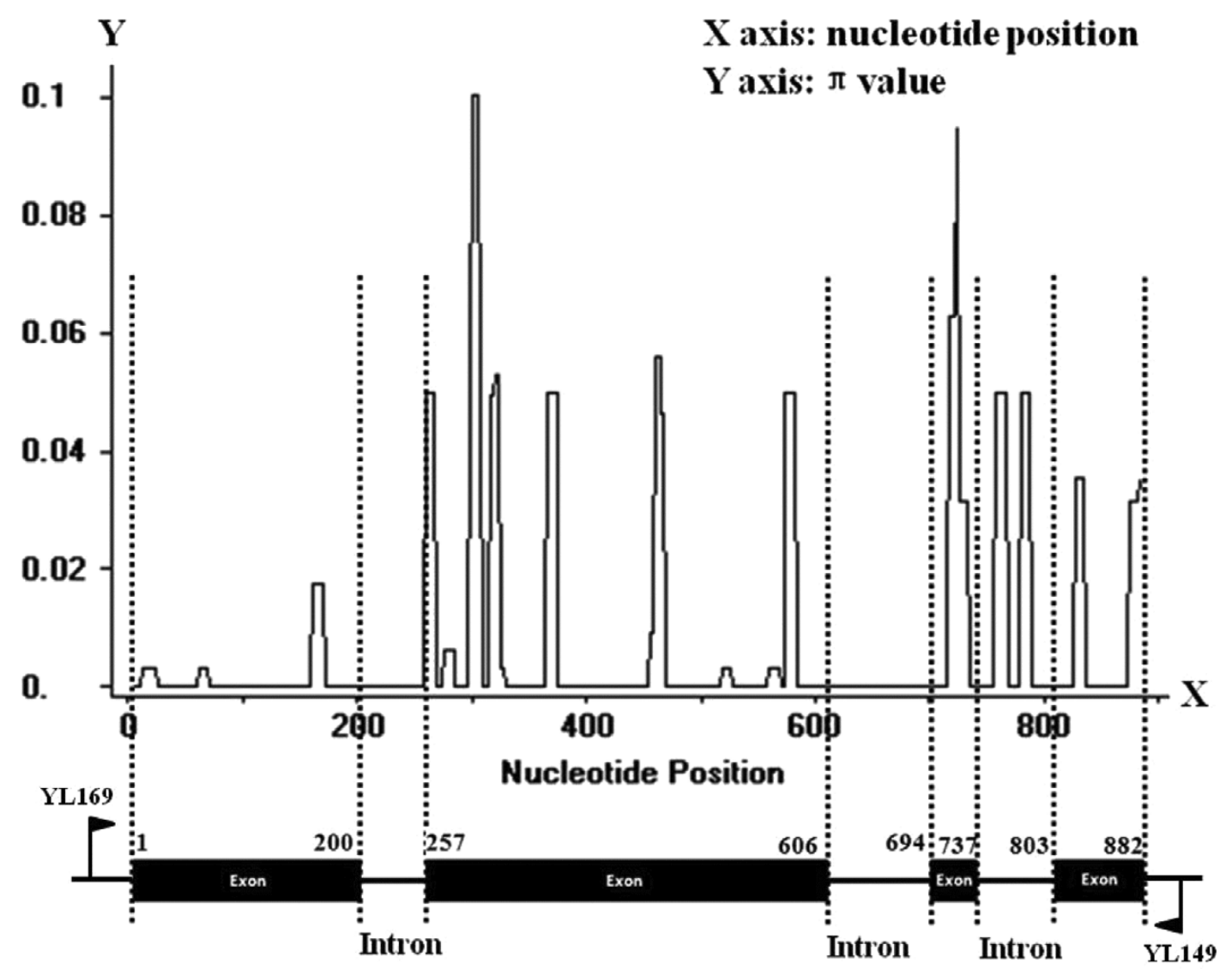

Fig. 1. Diversification of AVR-Pital in avirulent isolates. Distribution of variation of the AVR-Pital alleles was analyzed using a sliding window. X-axis shows the distribution of variation within the full region, including three introns and four exons of AVR-Pital. Lower pane indicates the corresponding schematic presentation of the three introns and four exons of AVR-Pital. Window length $=10$; step size $=2 ; \pi$ value corresponds with the level of variation at each site because it is the sum of pairwise differences divided by the number of pairs within the population.

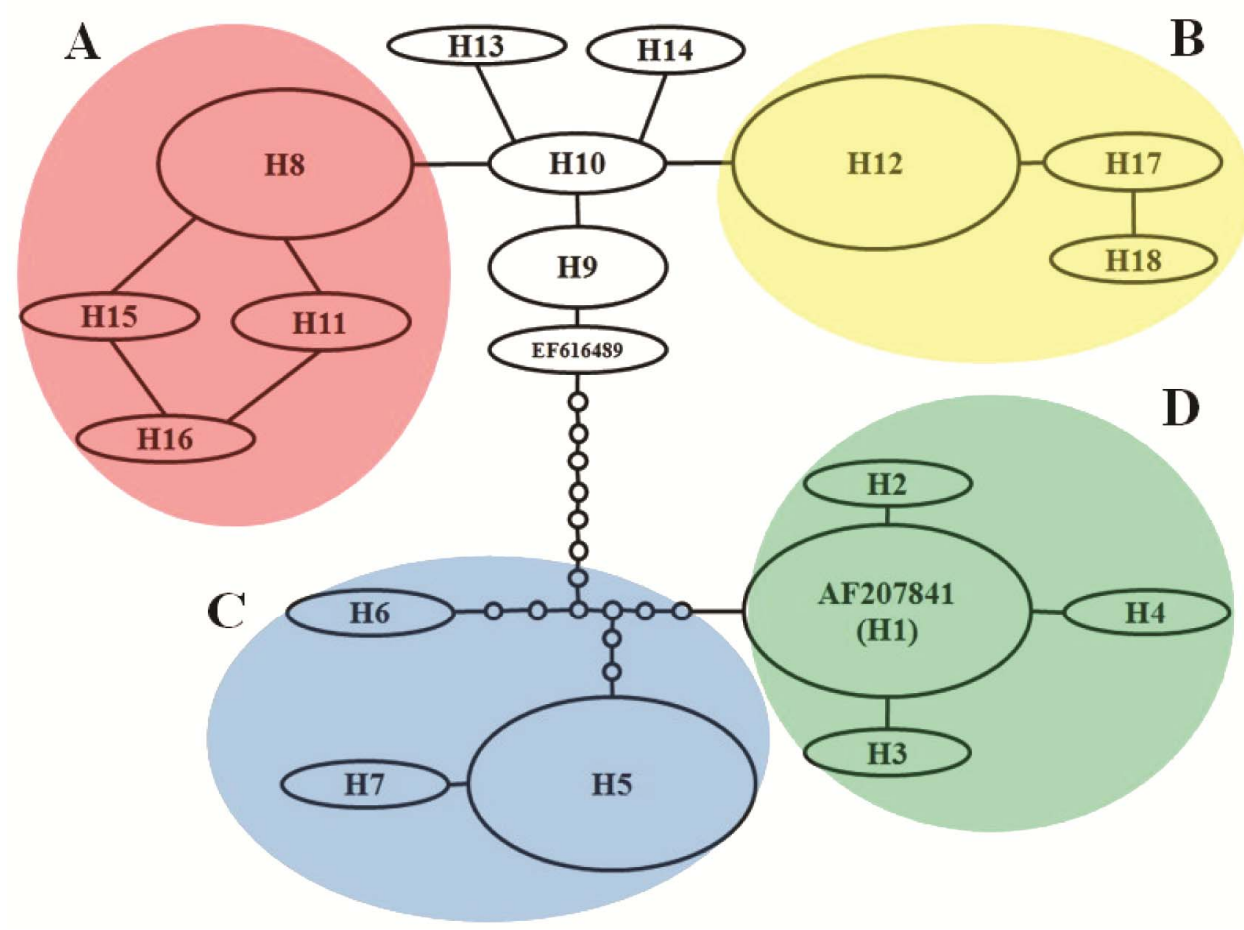

Fig. 2. Haplotype network for the 18 AVR-Pital alleles. The original AVR-Pital allele was designated as the H10 haplotype in the network. A blank node in the network represents an extinct or missing haplotype not found in the sample. Each haplotype was separated by mutational events. All haplotypes are displayed as circles. The size of the circles corresponds to the haplotype frequency. The haplotype EF616489 (GenBank accession number EF616489) of AVR-Pital was obtained from GenBank. A to D, Four major haplotypes of AVR-Pital in Yunnan Province of China are shaded. 


\begin{tabular}{|c|c|c|c|c|c|c|c|c|c|c|c|c|c|c|c|c|c|c|}
\hline \multirow[b]{3}{*}{ Haplotype } & \multicolumn{17}{|c|}{ Locus } & \multirow[b]{3}{*}{$\mathrm{DR}^{\mathrm{b}}$} \\
\hline & \multicolumn{2}{|c|}{ Exon 1} & \multicolumn{11}{|c|}{ Exon2 } & \multicolumn{2}{|c|}{ Exon3 } & \multicolumn{2}{|c|}{ Exon4 } & \\
\hline & $5-6$ & 55 & 74 & 81 & 82 & 87 & 88 & 103 & 134 & 135 & 154 & 168 & 173 & 191 & 194 & 206 & 222 & \\
\hline AF207841 & - & $\mathrm{D}$ & $\mathrm{W}$ & $\mathrm{N}$ & $\mathrm{D}$ & $\mathrm{R}$ & $\mathrm{L}$ & $\mathrm{K}$ & $\mathrm{E}$ & $\mathrm{G}$ & $\mathrm{P}$ & $\mathrm{G}$ & V & $\mathrm{Y}$ & $\mathrm{D}$ & $\mathrm{K}$ & $\mathrm{Y}$ & $\ldots$ \\
\hline EF616489 & $\mathrm{L}$ & . & . & $\mathrm{S}$ & . & $\mathrm{K}$ & . & $\mathrm{N}$ & . & $\mathrm{E}$ & . & . & I & . & . & . & . & $\ldots$ \\
\hline H01 & - & . & . & . & . & . & . & . & . & . & . & . & . & . & . & . & . & $10 \mathrm{R}$ \\
\hline H02 & - & . & . & . & . & . & . & . & . & . & . & . & . & . & . & . & . & $1 \mathrm{R}$ \\
\hline H03 & - & $\mathrm{N}$ & . & . & . & . & . & . & . & . & . & . & . & . & . & . & . & $1 \mathrm{~S}$ \\
\hline H04 & - & . & . & . & . & . & . & . & . & . & . & . & . & . & . & . & . & $1 \mathrm{R}$ \\
\hline H05 & $\mathrm{L}$ & . & . & . & . & . & . & . & . & . & . & . & . & $\mathrm{F}$ & $\mathrm{H}$ & . & $\mathrm{N}$ & $11 \mathrm{R}$ \\
\hline H06 & $\mathrm{L}$ & . & . & . & . & $\mathrm{K}$ & $\mathrm{S}$ & . & . & . & $\mathrm{R}$ & V & . & . & . & . & . & $1 \mathrm{R}$ \\
\hline H07 & $\mathrm{L}$ & . & $\mathrm{G}$ & . & . & . & . & . & . & . & . & . & . & $\mathrm{F}$ & $\mathrm{H}$ & . & $\mathrm{N}$ & $1 \mathrm{R}$ \\
\hline H08 & $\mathrm{L}$ & . & . & $\mathrm{S}$ & $\mathrm{N}$ & $\mathrm{K}$ & . & $\mathrm{N}$ & . & . & . & . & I & $\mathrm{C}$ & . & . & . & $8 \mathrm{M}+1 ?$ \\
\hline H09 & $\mathrm{L}$ & . & . & $\mathrm{S}$ & $\mathrm{N}$ & $\mathrm{K}$ & . & $\mathrm{N}$ & . & $\mathrm{E}$ & . & . & I & . & . & . & . & $2 \mathrm{R}+1 ?$ \\
\hline $\mathrm{H} 10$ & $\mathrm{~L}$ & . & . & $\mathrm{S}$ & $\mathrm{N}$ & $\mathrm{K}$ & . & $\mathrm{N}$ & . & $\mathrm{E}$ & . & . & I & $\mathrm{C}$ & . & . & . & $1 \mathrm{R}$ \\
\hline H13 & $\mathrm{L}$ & . & . & $\mathrm{S}$ & $\mathrm{N}$ & $\mathrm{K}$ & . & $\mathrm{N}$ & . & $\mathrm{E}$ & . & . & I & $\mathrm{C}$ & . & . & . & $1 \mathrm{R}$ \\
\hline H14 & $\mathrm{L}$ & . & . & $\mathrm{S}$ & $\mathrm{N}$ & $\mathrm{K}$ & . & $\mathrm{N}$ & . & $\mathrm{E}$ & . & . & I & $\mathrm{C}$ & . & . & . & $1 \mathrm{R}$ \\
\hline H11 & $\mathrm{L}$ & . & . & $\mathrm{S}$ & $\mathrm{N}$ & $\mathrm{K}$ & . & $\mathrm{N}$ & $\mathrm{Q}$ & . & . & . & I & $\mathrm{C}$ & . & . & . & $1 \mathrm{~S}+1 ?$ \\
\hline H12 & $\mathrm{L}$ & . & . & $\mathrm{S}$ & $\mathrm{N}$ & $\mathrm{K}$ & . & $\mathrm{N}$ & . & $\mathrm{E}$ & . & . & I & $\mathrm{C}$ & . & $\mathrm{R}$ & . & $11 \mathrm{M}+1 ?$ \\
\hline H15 & $\mathrm{L}$ & $\mathrm{N}$ & . & $\mathrm{S}$ & $\mathrm{N}$ & $\mathrm{K}$ & . & $\mathrm{N}$ & . & . & . & . & I & $\mathrm{C}$ & . & . & . & $1 \mathrm{~S}$ \\
\hline H16 & $\mathrm{L}$ & $\mathrm{N}$ & . & $\mathrm{S}$ & $\mathrm{N}$ & $\mathrm{K}$ & . & $\mathrm{N}$ & Q & . & . & . & I & $\mathrm{C}$ & . & . & . & $1 \mathrm{~S}$ \\
\hline H17 & $\mathrm{L}$ & $\mathrm{N}$ & . & $\mathrm{S}$ & $\mathrm{N}$ & $\mathrm{K}$ & . & $\mathrm{N}$ & . & $E$ & . & . & I & $\mathrm{C}$ & . & $\mathrm{R}$ & . & $2 S$ \\
\hline H18 & $\mathrm{L}$ & $\mathrm{N}$ & $\mathrm{G}$ & $\mathrm{S}$ & $\mathrm{N}$ & $\mathrm{K}$ & . & $\mathrm{N}$ & . & $\mathrm{E}$ & . & . & I & $\mathrm{C}$ & . & $\mathrm{R}$ & . & $1 ?$ \\
\hline
\end{tabular}

a Symbols: . indicates the same as AF207841 and - indicates deletion.

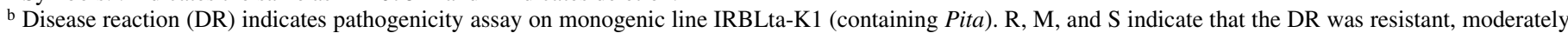
resistant, or susceptible, respectively; Ex.10R indicates 10 isolates were avirulent to IRBLta-K1; and ? indicates unknown.

TABLE 5. Correlation of disease reaction of the isolate with or without $A V R$ Pital of Magnaporthe oryzae by polymerase chain reaction (PCR) detection and pathogenicity assay

\begin{tabular}{|c|c|c|c|c|}
\hline \multirow[b]{3}{*}{ Isolates } & \multicolumn{4}{|c|}{ Reaction types ${ }^{\mathrm{a}}$} \\
\hline & \multicolumn{2}{|c|}{ Consistent } & \multicolumn{2}{|c|}{ Inconsistent } \\
\hline & $\mathrm{A}+$ & $\mathrm{V}-$ & $\mathrm{V}+$ & A- \\
\hline Number & 152 & 61 & 66 & 87 \\
\hline Total & \multicolumn{2}{|c|}{213} & \multicolumn{2}{|c|}{153} \\
\hline Percentage (\%) & \multicolumn{2}{|c|}{58.2} & \multicolumn{2}{|c|}{41.8} \\
\hline
\end{tabular}

a A+ indicates isolates with AVR-Pital by PCR detection and avirulent to the corresponding resistance $(R)$ gene; $\mathrm{V}$ - indicates isolates without AVR-Pital by PCR detection and virulent to the corresponding $R$ gene; $\mathrm{V}+$ indicates isolates with AVR-Pital by PCR detection and virulent to the corresponding $R$ gene; and $\mathrm{A}$ - indicates without AVR-Pital by PCR detection and avirulent to the corresponding $R$ gene.

appeared as inconsistent with the gene-for-gene theory (Table 6), suggesting that virulent isolates to $P i$-ta have been accumulated and genome organization at the AVR-Pital locus is much more complex in Yunnan than predicted.

\section{DISCUSSION}

In the present study, we found new changes in the AVR-Pital sequences among field isolates of $M$. oryzae from various riceproducing regions in Yunnan, China, and a mass of virulence isolates to $P i$-ta gene were identified in field isolates collected in Yunnan, suggesting that $P i$-ta was defeated in some rice production areas due to extensive development of $\mathrm{Pi}$-ta in China. Pi$t a$ was effectively deployed in the United States over two decades ago $(14,21)$ and is still effective in the United States (Y. Jia, unpublished data). Partial deletions, complete deletions, frameshift mutations, and sequence variations have occurred in $A V R$ Pital sequences among field isolates of $M$.oryzae from various rice-producing countries (5). However, a majority of isolates surveyed from commercial rice fields, thus far, still contain a functional AVR-Pital. Rice cultivars with Pi-ta were resistant to $75.1 \%$ of isolates (282 isolates) in Yunnan (18) and $18.5 \%$ of isolates (146 isolates) from Guangdong province, China (34), suggesting that $P i$-ta has a limited effect in these rice production areas. Continued analysis of AVR-Pital in these isolates will help us to predict the stability and effectiveness of $\mathrm{Pi}$-ta mediated resistance.

Gene-for-gene theory predicts that $P i$-ta specifically prevents the infections by isolates of M. oryzae that contain AVR-Pital. M. oryzae isolates without AVR-Pital are avirulent to IRBLta-K1 (with $P i$-ta), suggesting that IRBLta-K1 also contains Pi-taindependent blast $R$ genes (Table 1). However, nine isolates with AVR-Pital in the southeastern region of Yunnan infected IRBLta$\mathrm{K} 1$. One possibility is that expression of these AVR-Pital alleles may be hindered. Further examination of the promoter regions and expressions of these AVR-Pital alleles should help to verify this prediction.

Most DNA sequence variation was found in exon regions of AVR-Pital, and 18 haplotypes were identified based on the 25 variant nucleotides (included insertion/deletion) among 60 isolates collected from Yunnan province (Table 2). Five novel variant amino acids (D55N, W74G, L88S, E134Q, and Y222N) of the AVR-Pital variants in the 60 isolates were identified. Among them, 55D may be another critical amino acid for avirulent function because the isolates were virulent to IRBLta-K1 (Pi-ta) when 55D was replaced with 55N (Table 4). The amino acid V or I at position 173 was a critical amino acid residue for metalloprotease (9). We also identified $\mathrm{V}$ in 26 isolates and I in 34 isolates at position 173 of the metalloprotease motif of AVR-Pita1 in an isolate population (Tables 3 and 4). Similarly, the structures of the AVR-Pita alleles in 39 U.S. isolates of M. oryzae were analyzed. Five alleles were predicted to encode metalloprotease proteins highly similar to the AVR-Pita protein (5). An avirulent isolate, OS99-G-7a (G7a), from a Japanese commercial field containing two paralogs of AVR-Pital (AVR-Pital ${ }^{J A}$ and AVRPita $^{J B}$ ) was identified. Isolates that showed virulence toward rice cultivars containing the $P i$-ta gene were presumed to have evolved virulence from avirulent origins via loss of $A V R$-Pita ${ }^{J A}$, except for one case in which virulence resulted from a base substitution (30).

Various mechanisms, including the mobility of active transposable elements, have been theorized to explain the instability of this fungus. A Pot3 transposon was identified in the DNA region encoding the putative protease motif of the AVR-Pita protein from a field isolate B2 collected from a Pi-ta-containing 'Banks' rice. 


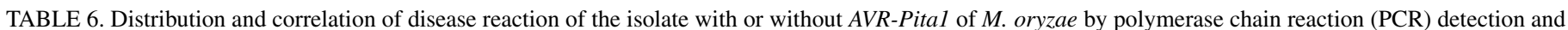
pathogenicity assay

\begin{tabular}{|c|c|c|c|c|c|c|}
\hline \multirow[b]{2}{*}{ Locations } & \multirow[b]{2}{*}{ Number of isolates } & \multicolumn{5}{|c|}{ Reaction types of isolates and frequency $(\%)^{\mathrm{a}}$} \\
\hline & & $\mathrm{A}+$ & $\mathrm{V}-$ & $\mathrm{V}+$ & A- & Total \\
\hline Northeastern & 72 & 41 & 10 & $4(5.6)$ & $17(23.6)$ & $21(29.2)$ \\
\hline Southeast & 32 & 7 & 12 & $11(34.4)$ & $2(6.3)$ & $13(40.7)$ \\
\hline Western & 164 & 70 & 28 & $26(15.9)$ & $40(24.4)$ & $66(40.3)$ \\
\hline Northwest & 15 & 4 & 1 & $3(20.0)$ & $7(46.7)$ & $10(66.7)$ \\
\hline Southwestern & 29 & 13 & 3 & $8(27.6)$ & $5(17.2)$ & $13(44.8)$ \\
\hline Central & 54 & 17 & 7 & $14(25.9)$ & $16(29.6)$ & $30(55.5)$ \\
\hline Total & 366 & 152 & 61 & $66(18.0)$ & $87(23.8)$ & $153(41.8)$ \\
\hline
\end{tabular}

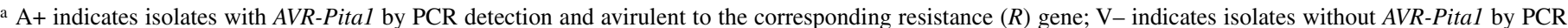
detection and virulent to the corresponding $R$ gene; $\mathrm{V}+$ indicates isolates with $A V R$-Pital by PCR detection and virulent to the corresponding $R$ gene; Aindicates without $A V R$-Pital by PCR detection and avirulent to the corresponding $R$ gene.

Similarly, the insertion of retrotransposon in ACE1 was hypothesized to result from avirulence to virulence (8). Virulent isolates were found to exhibit either a Pot3 insertion in the promoter region or single-nucleotide substitution resulting in an amino acid change in AVR-Pizt (20). Transposon and telomeric sequences in the genomic regions neighboring AVR-Pia and AVR-Pii led to the enhanced likelihood of gene loss and horizontal transfer $(24,26)$. These findings demonstrated that transposons can contribute to the instability of $A V R$ genes in $M$. oryzae and is one important molecular mechanism for defeating $R$ genes in rice cultivars.

Plants and pathogens have coexisted and coevolved. There are two predominant hypotheses for the co-evolution of $R$ genes in plants and $A V R$ genes in pathogens. The foremost hypothesis is the "arms race" that predicts that both $R$ and $A V R$ genes are under diversified selection, whereas a "trench warfare" hypothesis predicts that either $R$ or $A V R$ is under balanced selection and the other is under diversified selection. To date, direct interactions of AVR-Pita with Pi-ta and AVR-Pik and Pi-k, and indirect interaction of AVR-Pizt and Pi-zt, have been reported $(1,12,23)$. Directional selection was found in the $P i$-ta region in accessions of Oryza rufipogon, whereas significant deviation from neutral evolution was not found in accessions of $O$. sativa $(10,17)$. AVRPita is located near the telomere, an unstable region $(16,22)$; the presence of multiple AVR-Pital variants in avirulent field isolates appears to suggest the 'arms race occurs between Pi-ta and AVRPital if similar numbers of resistant and susceptible alleles can be found at the Pi-ta locus. Sequence variation observed in flanking regions around $P i-t a$ in $O$. sativa suggest that the size of the resistance $P i$-ta introgressed block was at least $5.4 \mathrm{Mb}$ in all elite resistant cultivars but not in the cultivars without Pi-ta. These findings suggest that the $P i$-ta region has evolved under extensive selection pressure during crop breeding for resistance $(11,17)$. Despite this, it is still difficult to determine whether a balanced or an unbalanced selection has occurred at the Pi-ta region. The absence of multiple resistant $P i$-ta haplotypes suggests that $P i$-ta engages trench warfare with AVR-Pital. Similarly, RGA4 and $R G A 5$ encode two predicted nucleotide-binding LRR proteins that were demonstrated to recognize the two unrelated effector molecules, AVR1-CO39 and AVR-Pia of M. oryzae, indicating that the $\mathrm{R}$ proteins may possess dual recognition specificity (2). Pi-ta was predicted to encode 12 transcripts, most of which could encode nucleotide-binding site LRR proteins (4), suggesting that they may recognize different AVR-Pital haplotypes or different $A V R$ genes. Continued analysis of the Pi-ta allele in rice germplasm and examination of functionality of these Pi-ta alternative transcripts will lead to a hypothesis that Pi-ta engages in an arms race with AVR-Pita1 at a transcriptional level.

In summary, we demonstrated that the Pi-ta gene is effective in significant portions of rice production areas in Yunnan province. Our findings support the idea that a functional AVR-Pital possesses diversified sequence structures and is under positive selection pressure in nature. Our results are consistent with previous findings in field isolates, and declaim the molecular mechanisms of AVR-Pital diversification in nature.

\section{ACKNOWLEDGMENTS}

This manuscript was selected as a feature article through the APSCSPP Cooperative Agreement. This work was supported by the National Natural Science Foundation of China (31160355). We thank T. Bianco and M. Lin of the United States Department of Agriculture-Agricultural Research Service Dale Bumpers National Rice Research Center for excellent technical assistance; Z. Cheng of Institute of Biotechnology and Genetic Resources, Yunnan Academy of Agricultural Sciences; and Y. Guo of Yunnan Agricultural University for useful discussions. The United States Department of Agriculture is an equal opportunity provider and employer.

\section{LITERATURE CITED}

1. Bryan, G. T., Wu, K., Farrall, L., Jia, Y., Hershey, H. P., McAdams, S. A., Faulk, K. N., Donaldson, G. K., Tarchini, R., and Valent, B. 2000. A single amino acid difference distinguishes resistant and susceptible alleles of rice blast resistance gene Pi-ta. Plant Cell 12:2033-2045.

2. Cesari, S., Thilliez, G., Ribot, C., Chalvon, V., Michel, C., Jauneau, A., Rivas, S., Alaux, L., Kanzaki, H., Okuyama, Y., Morel, J., Fournier, E., Tharreau, D., Terauchi, R., and Kroj, T. 2013. The rice resistance protein pair RGA4/RGA5 recognizes the Magnaporthe oryzae effectors AVR-Pia and AVR1-CO39 by direct binding. Plant Cell 25:1463-1481.

3. Clement, M., Posada, D., and Crandall, K. 2000. TCS: a computer program to estimate gene genealogies. Mol. Ecol. 9:1657-1659.

4. Costanzo, S., and Jia, Y. 2009. Alternatively spliced transcripts of Pi-ta blast resistance gene in Oryza sativa. Plant Sci. 177:468-478.

5. Dai, Y., Jia, Y., Correll, J., Wang, X., and Wang, Y. 2010. Diversification evolution of the avirulence gene AVR-Pital in field isolates of Magnaporthe oryzae. Fungal Genet. Biol. 47:974-980.

6. Farman, M. L., and Leong, S. A. 1998. Chromosome walking to the AVR1-CO39 avirulence gene of Magnaporthe grisea: discrepancy between the physical and genetic maps. Genetics 150:1049-1058.

7. Fontaine, C., Lovett, P. N., Sanou, H., Maley, J., and Bouvet, J.-M. 2004. Genetic diversity of the shea tree (Vitellaria paradoxa C. F. Gaertn), detected by RAPD and chloroplast microsatellite markers. Heredity 93:639-648.

8. Fudal, I., Bohnert, H. U., Tharreau, D., and Lebrun, M. H. 2005. Transposition of MINE, a composite retrotransposon, in the avirulence gene $A C E 1$ of the rice blast fungus Magnaporthe grisea. Fungal Genet. Biol. 42:761-772.

9. Hofmann, K., Bucher, P., Falquet, L., and Bairoch, A. 1999. The PROSITE database, its status in 1999. Nucleic Acids Res. 27:215-219.

10. Huang, C. L., Hwang, S. Y., Chiang, Y. C., and Lin, T. P. 2008. Molecular evolution of the Pi-ta gene resistant to rice blast in wild rice (Oryza rufipogon). Genetics 179:1527-1538.

11. Jia, Y. 2009. Artificial introgression of a large fragment around the Pi-ta rice blast resistance gene in backcross progenies and several elite rice cultivars. Heredity 103:333-339.

12. Jia, Y., McAdams, S., Bryan, G., Hershey, H., and Valent, B. 2000. Direct interaction of resistance gene and avirulence gene products confers rice blast resistance. EMBO J. 19:4004-4014.

13. Jia, Y., Valent, B., and Lee, F. N. 2003. Determination of host responses to Magnaporthe grisea on detached rice leaves using a spot inoculation method. Plant Dis. 87:129-133. 
14. Jia, Y., Wang, Z., Fjellstrom, R. G., Moldenhauer, K. A., Azam, M. A., Correll, J., Lee, F. N., Xia, Y., and Rutger, J. N. 2004. Rice Pi-ta gene confers resistance to the major pathotypes of the rice blast fungus in the United States. Phytopathology 94:296-301.

15. Kang, S., Sweigard, J. A., and Valent, B. 1995. The $P W L$ host specificity gene family in the blast fungus Magnaporthe grisea. Mol. Plant-Microbe Interact. 8:939-948.

16. Khang, C. H., Park, S. Y., Lee, Y. H., Valent, B., and Kang, S. 2008. Genome organization and evolution of the AVR-Pita avirulence gene family in the Magnaporthe grisea species complex. Mol. Plant-Microbe Interact. 21:658-670.

17. Lee, S., Costanzo, S., Jia, Y., Olsen, K. M., and Caicedo, A. L. 2009. Evolutionary dynamics of the genomic region around the blast resistance gene Pi-ta in AA genome Oryza species. Genetics 183:1315-1325.

18. Li, J., Li, C., Chen, Y., Lei, C., and Ling, Z. 2005. Evaluation of twentytwo blast resistance genes in Yunnan using monogenetic rice lines. Acta Phytophylac. Sin. 32:113-119.

19. Li, J., Wang, T., and Xu, M. 2012. Identification of Pi-ta and Pi-b genes for rice blast resistance of rice varieties from Yunnan province. Chin. J. Rice Sci. 26:593-599.

20. Li, W., Wang, B., Wu, J., Lu, G., Hu, Y., Zhang, X., Zhang, Z., Zhao, Q., Feng, Q., Zhang, H., Wang, Z., Wang, G. L., Han, B., Wang, Z., and Zhou, B. 2009. The Magnaporthe oryzae avirulence gene AVR-Pizt encodes a predicted secreted protein that triggers the immunity in rice mediated by the blast resistance gene Piz-t. Mol. Plant-Microbe Interact. 22:411-420.

21. Moldenhauer, K. A. K., Lee, F. N., Norman. R. J., Helms, R. S., Well, R. H., Dilday, R. H., Rohman, P. C., and Marchetti, M. A. 1990. Registration of 'Katy' rice. Crop Sci. 30:747-748.

22. Orbach, M. J., Farrall, L., Sweigard, J. A., Chumley, F. G., and Valent, B. 2000. A telomeric avirulence gene determines efficacy for the rice blast resistance gene $\mathrm{Pi}$-ta. Plant Cell 12:2019-2032.

23. Park, C. H., Chen, S., Shirsekar, G., Zhou, B., Khang, C. H., Songkumarn, P., Afzal, A. J., Ning, Y., Wang, R., Bellizzi, M., Valent, B., and Wang G. L. 2012. The Magnaporthe oryzae effector AvrPiz-t targets the RING E3 ubiquitin ligase APIP6 to suppress PAMP-triggered immunity in rice. Plant Cell 24:4748-4762.
24. Rehmeyer, C., Li, W., Kusaba, M., Kim, Y. S., Brown, D., Staben, C. Dean, R., and Farman, M. 2006. Organization of chromosome ends in the rice blast fungus, Magnaporthe oryzae. Nucleic Acids Res. 34:4685-4701.

25. Rozas, J., Sánchez-DelBarrio, J., Messeguer, X., and Rozas, R. 2003. DnaSP, DNA polymorphism analyses by the coalescent and other methods. Bioinformatics 19:2496-2497.

26. Silva, J. C., Loreto, E. L., and Clark, J. B. 2004. Factors that affect the horizontal transfer of transposable elements. Curr. Issues Mol. Biol. 6:5772.

27. Sun, G., Jin, C., Chen, T., Liu, J., Ren, J., Liu, X., Zhang, S., and Pan, H. 2011. Molecular detection of avirulence genes and analysis of DNA fingerprint based on avirulence genes of Magnaporthe grisea. Biotechnol. Bull. 6:122-126.

28. Sweigard, J. A. 1995. Identification, cloning, and characterization of $P W L 2$, a gene for host species specificity in the rice blast fungus. Plant Cell 7:1221-1233.

29. Tai, T., and Tanksley, S. D. 1990. A rapid and inexpensive method for isolation of total DNA from dehydrated plant tissue. Plant Mol. Biol. Rep. 8:297-303.

30. Takahashi, M., Ashizawa, T., Hiravae, K., Moriwaki, J., Sone, T., Sonoda, R., Noguchi, M. T., Nagashima, S., Ishikawa, K., and Arai, M. 2010. One of two major paralogs of AVR-Pital is functional in Japanese rice blast isolates. Phytopathology 100:612-618.

31. Yang, J., Yang, J. H., Wang, J., Fan, F., Zhu, J., Cao Q., Tian, S., and Zhong, W. 2011. Distribution of two blast resistant genes Pita and Pib in landrace rice in China. Acta Agric. Boreali Sin. 26:1-6.

32. Yoshida, K., Saitoh, H., Fujisawa, S., Kanzaki, H., Matsumura, H., Yoshida, K., Tosa, Y., Chuma, L., Takano, Y., Win, J., Kamoun, S., and Terauchi, R. 2009. Association genetics reveals three novel avirulence genes from the rice blast fungal pathogen Magnaporthe oryzae. Plant Cell 21:1573-1591.

33. Zhou, E., Jia, Y., Singh, P., Correll, J., and Lee, F. N. 2007. Instability of the Magnaporthe oryzae avirulence gene AVR-Pita alters virulence. Fungal Genet. Biol. 44:1024-1034.

34. Zhu, X., Yang, Q., Yang, J., Lei, C., Wang, J., and Ling, Z. 2004. Differentiation ability of monogenic lines to Magnaporthe grisea in indica rice. Acta Phytopathol. Sin. 34:361-368. 